\title{
LA-UR-12-24317
}

Approved for public release; distribution is unlimited.

Title:

Author(s):

Intended for:

\section{Agriculture and Food Security: Plant Disease Surveillance}

White, P Scott

Deshpande, Alina

Industry visitors shopping LANL technologies.

\section{- LOSAlamos \\ EST. 1943}

Disclaimer:

Los Alamos National Laboratory, an affirmative action/equal opportunity employer,is operated by the Los Alamos National

Security, LLC for the National NuclearSecurity Administration of the U.S. Department of Energy under contract DE-AC52-06NA25396.

By approving this article, the publisher recognizes that the U.S. Government retains nonexclusive, royalty-free license to

publish or reproduce the published form of this contribution, or to allow others to do so, for U.S. Government purposes.

Los Alamos National Laboratory requests that the publisher identify this article as work performed under the auspices of the

U.S. Departmentof Energy. Los Alamos National Laboratory strongly supports academic freedom and a researcher's right to publish; as an institution, however, the Laboratory does not endorse the viewpoint of a publication or guarantee its technical correctness. 


\title{
Agriculture and Food Security: Plant Disease Surveillance
}

\author{
BASF visit to LANL \\ 20 August 2012 \\ P Scott White, PhD \\ Team Leader for Global Security and Applications \\ B-7, Biosecurity and Public Health
}




\section{LANL Innovations in Bioscience Research \& Development High Impact Past and Exciting Future}

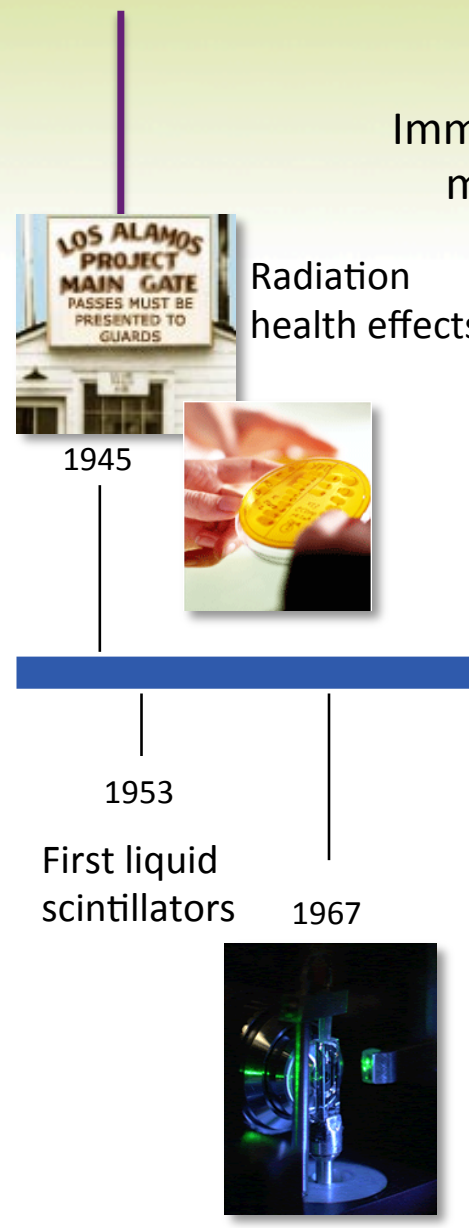

Development of Flow Cytometry

\section{modeling 1970}

$\mid$
GenBank

National Laboratory Gene Library Project

1983

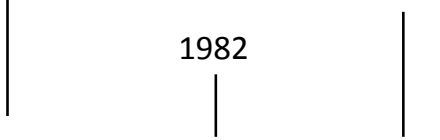

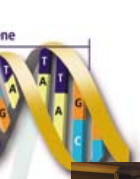

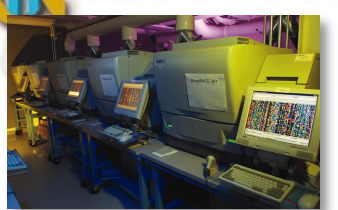
Human Genome Project

1988
Chromosome 16 Joint Genome Institute

1990's

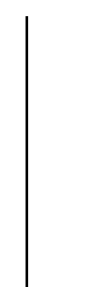

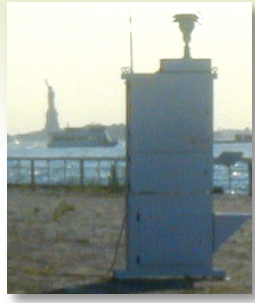

BioWatch

2004
High throughput flu lab

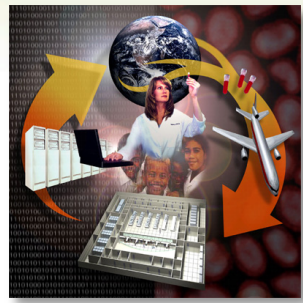

2008

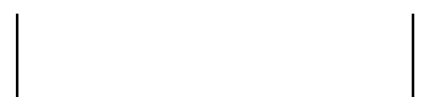

1980's-1990’s

Stable Isotope Resource

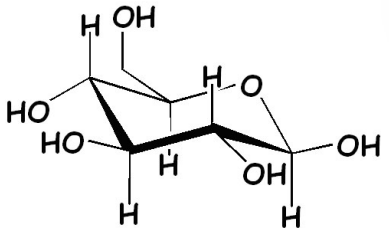

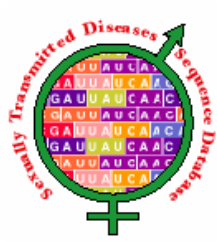

Genome databases

1986: HIV

1994: HPV

1996: Influenza

1998: STD

1999: Chem-Bio
2000

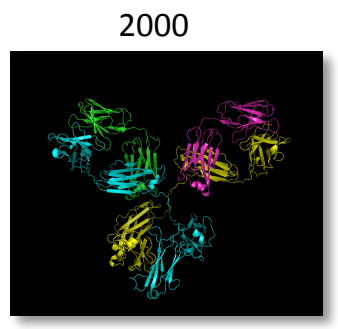

TB Structural Genomics Consortium

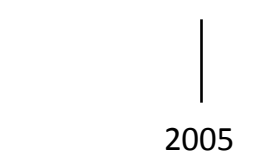

Bioforensics Analysis Research and Development Center

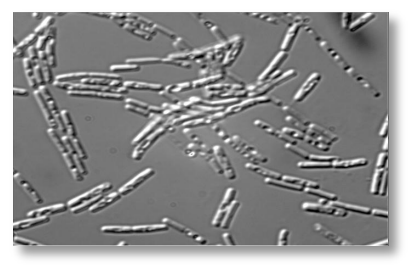




\section{Protecting high value crops}

Annual vs. perennial crops

- Crop rotation is an effective pest control for annual crops.

- Orchards/vineyards are developed over many years; no rotation relative to pathogen/vector life cycles.

- Trees/vines come into full production in 5-7 years.

- Breeding for resistance is an extremely slow process.

- Screening propagative material takes many weeks.

- Diseased trees serve as pathogen and vector reservoirs.

- Early detection and mitigation are critical for controlling disease spread. 


\section{Pathogens that threaten citrus}

Microbe/disease

1. Candidatus Liberibacter sp. - Huanglongbing (HLB); citrus greening

2. Xanthomonus citri - citrus canker

3. Citrus tristeza virus - citrus tristeza disease

4. Xylella fastidiosa - citrus variegated chlorosis

All are transmitted by insect vectors. Pathogens and vectors have many alternate hosts. 


\section{CTV worldwide distribution}

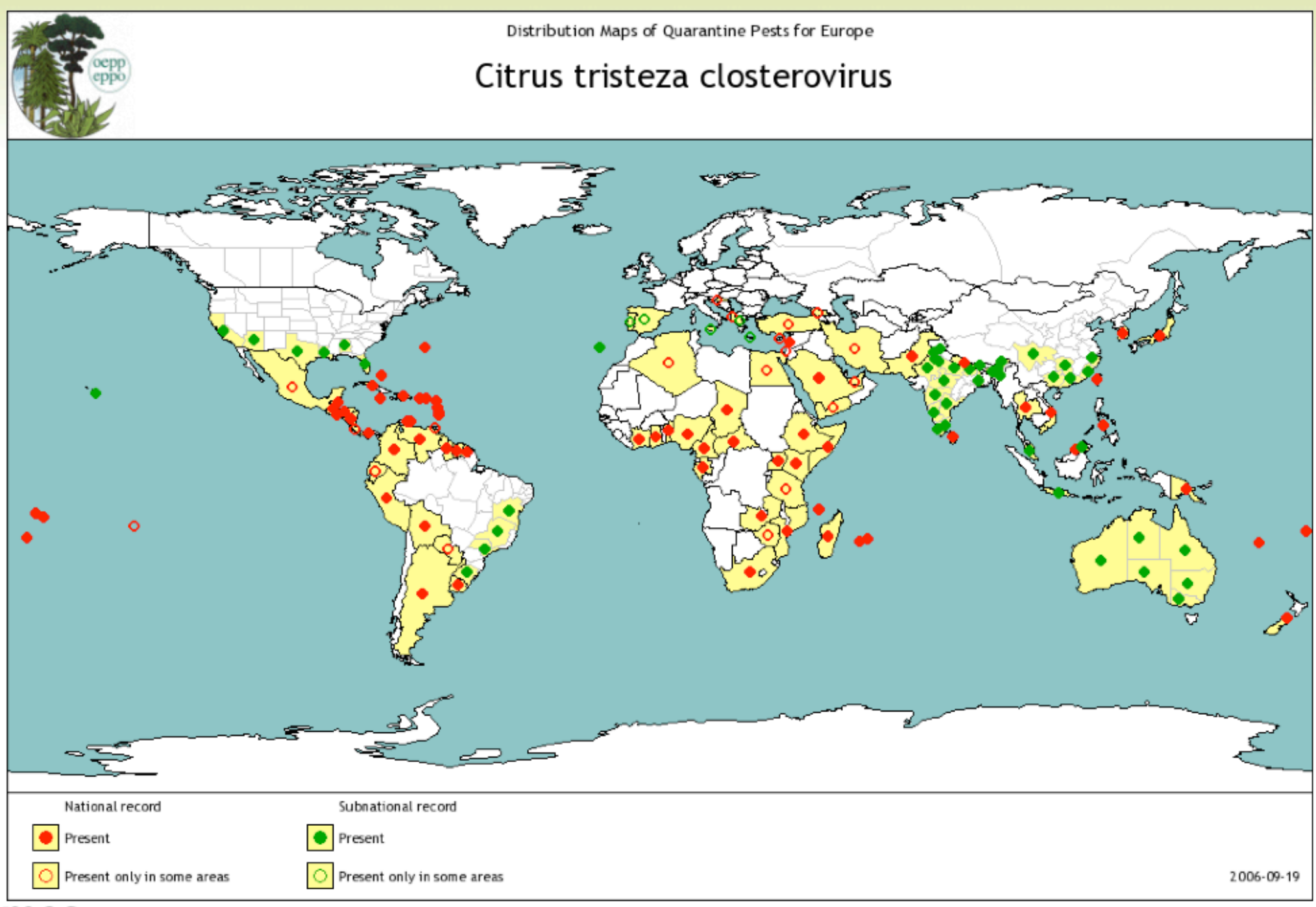




\section{Huanglongbing (HLB) distribution, US quarantine and impact}

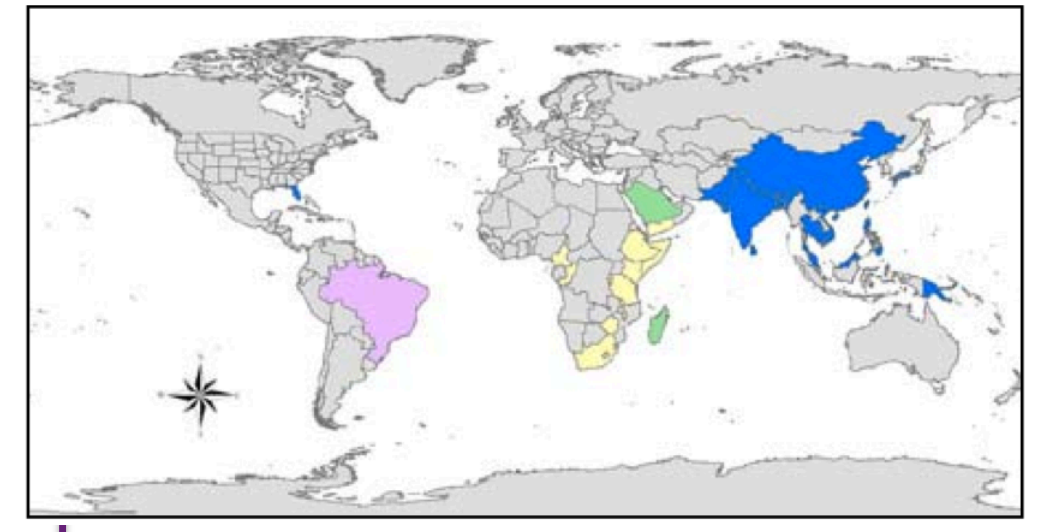

Figure 6. The worldwide distribution of HLB is shown with the following colors representing each of the strains or combinations of strains. $\square$ Asian strain of HLB. Asian and African strains of HLB. African strain of HLB.

Asian and American strains of HLB. Source: California Department of Food and Agriculture, GIS/GPS Laboratory.

\section{Citrus greening costs $\$ 3.63$ billion in lost revenues and} 6,611 jobs, new UF study shows

Filed under Agriculture, Business, Economic Impact, Florida, Research on Tuesday, January $24,2012$.

GAINESVILLE, Fla. - Since 2006, the bacterial disease citrus greening has cost Florida's economy an estimated $\$ 3.63$ billion in lost revenues and 6,611 jobs by reducing orange juice production, according to a new study from the University of Florida's Institute of Food and Agricultural Sciences.

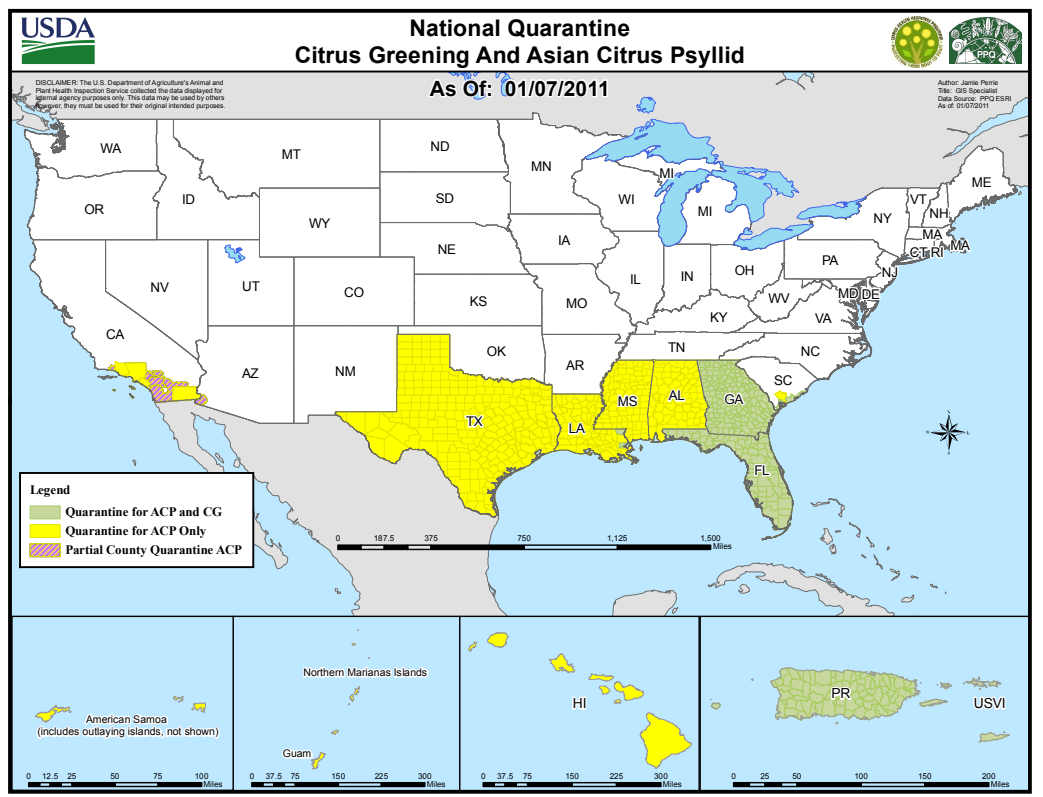

\section{- Los Alamos}




\section{Huanglongbing (HLB) in the USA}
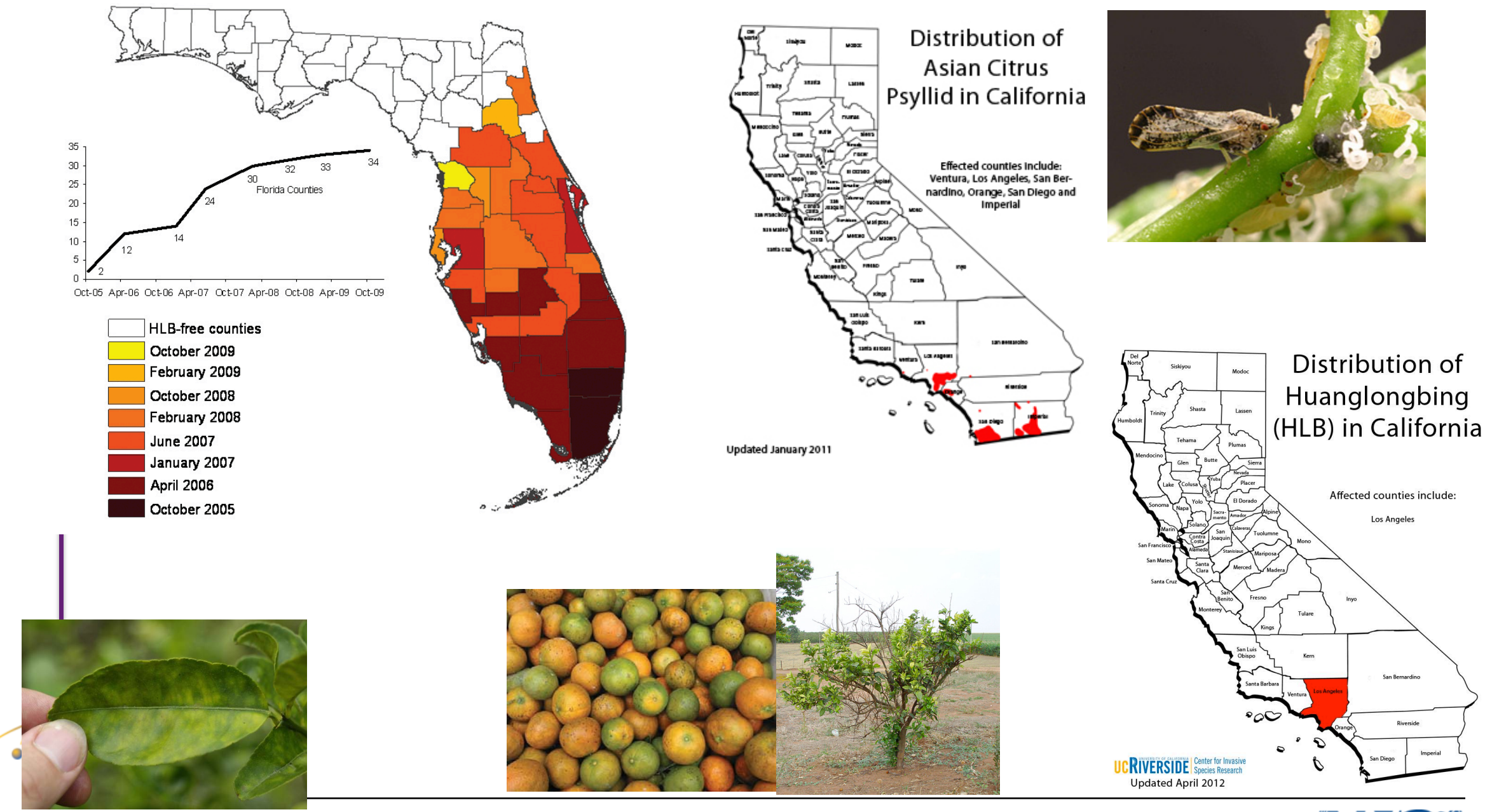


\section{Plant disease screening needs}

- Inexpensive, broad spectrum tests

- Presymptomatic detection where possible (testing insect vectors provides early warning)

- Rapid results

- Strain/species/subspecies specificity

- High throughput

- Automatable

- Flexible - add or change markers, as needed 


\section{Current methods for plant pathogen screening}

- Symptomatic diagnosis

- Inoculation of indicator plants

- ELISA

- PCR

-Whole genome sequencing?

Costs, cycle times, or lack of resolution present major limitations to collecting the large amount of data needed for global surveillance and security. 


\section{Multiplexing speeds diagnosis and response}

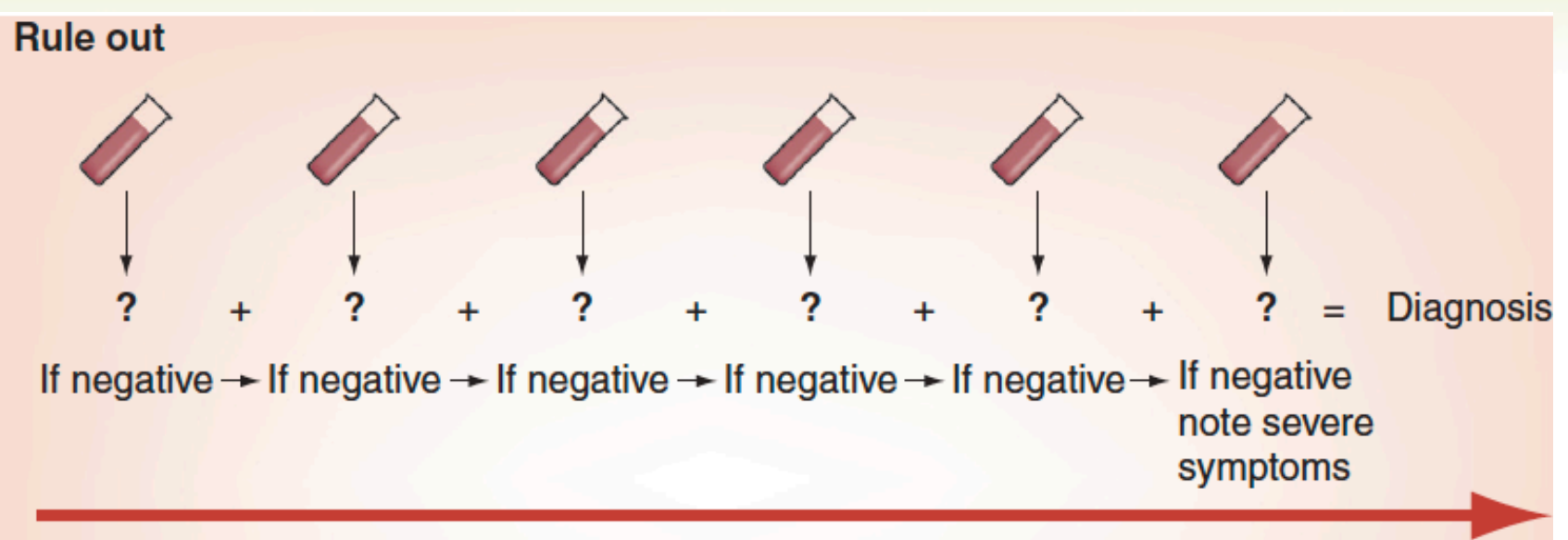

Time (days?)

Rule in

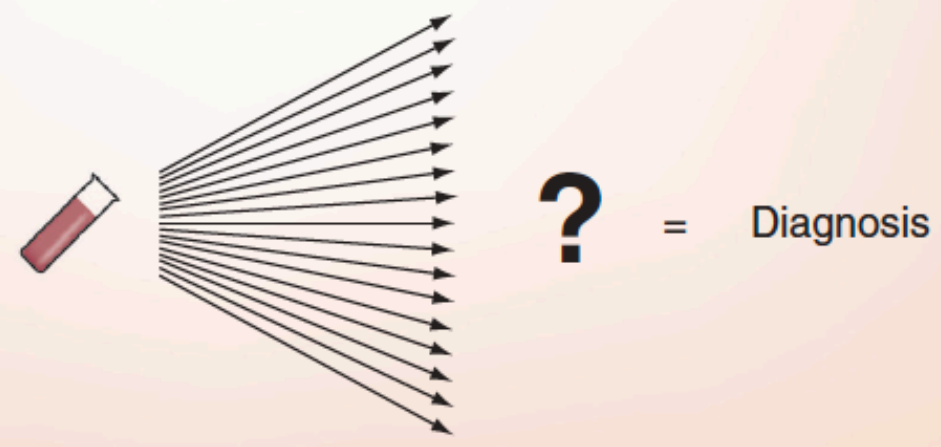

1 day or a few hours (minutes?) 


\section{Screening assay parameters: application-dependent}

\section{Citrus Pathogen Screening Specifications}

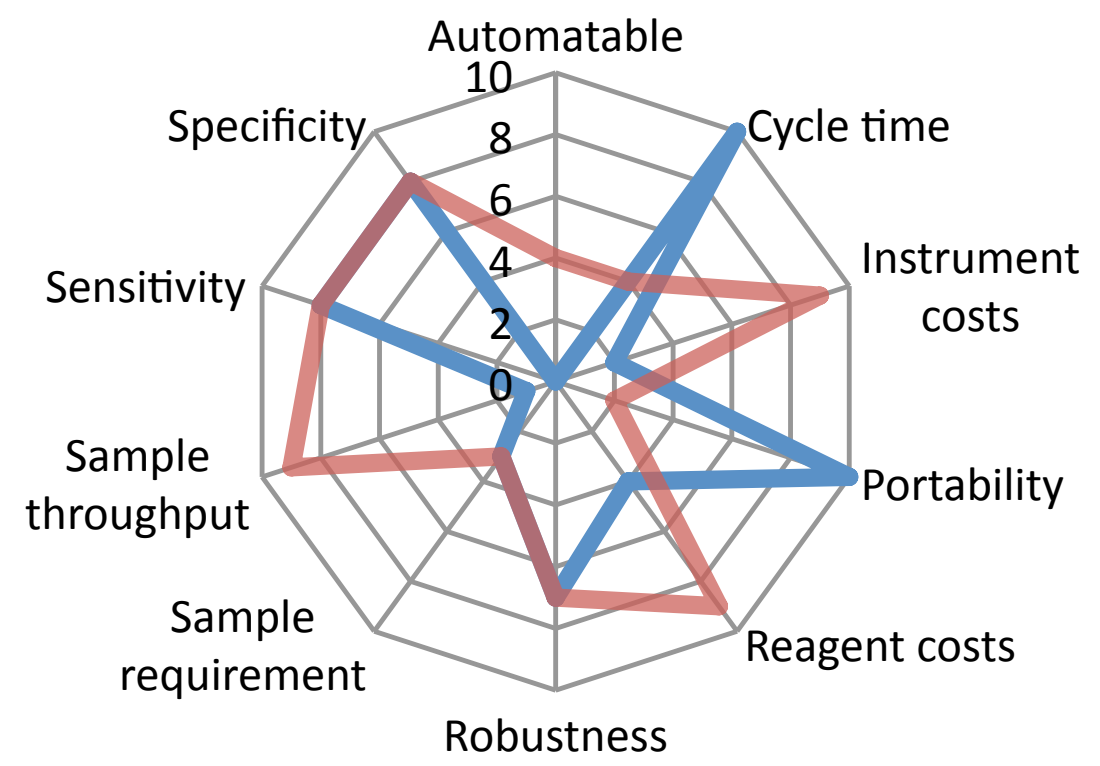

Field-based

Centralized lab

NOTE: the values in the graph are for illustration purposes only. Higher values represent higher level of importance of the corresponding parameter. 


\section{Plant pathogen screening process}

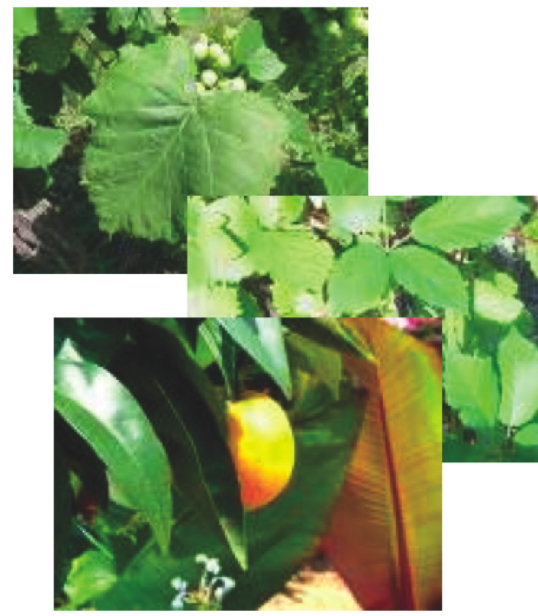

Collect field samples, transport to lab (via mail or hand-carry)

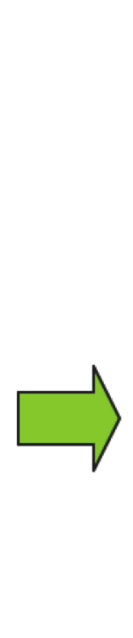

$$
\begin{gathered}
\text { Process } \\
\text { samples in } \\
\text { high throughput } \\
\text { laboratory } \\
\text { (up to thousands/day) }
\end{gathered}
$$

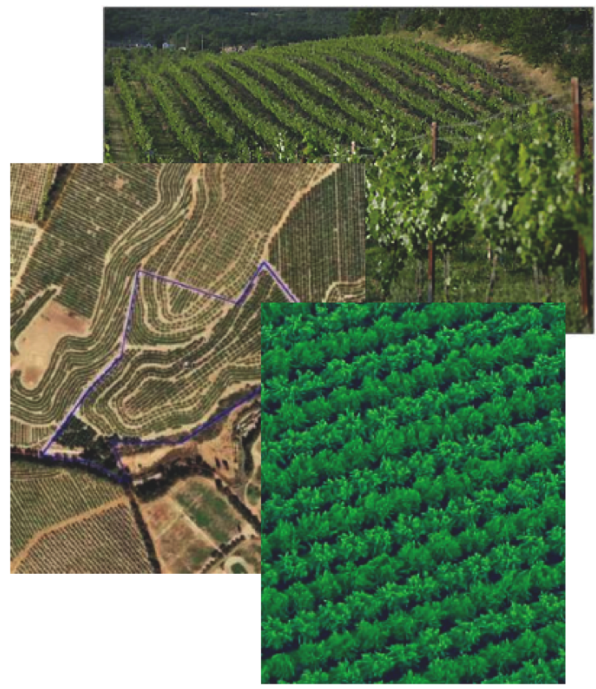

Management decisions based on rich data 


\section{Multiplex Oligonucleotide Ligation-Polymerase Chain Reaction (MOL-PCR): LANL-developed solution}

- Multidisciplinary technology developed over years

- Generic technology with many applications

- Genotyping, Marker Assisted Selection, ID and forensics

- Detection and diagnosis (human, ag, food safety, biothreat surveillance)

- Antibiotic/drug resistance determination

- Gene expression liquid arrays

- Many more

- Over $\$ 3 M$ in investments by DOE, LDRD, DHS S\&T, Citrus Research Board, and industry.

- Licensed to industry 


\section{MOL-PCR: an assay designed for multiplex}

\section{MOL-PCR: \\ Multiplex \\ Oligonucleotide Ligation-PCR}

This figure depicts a single marker, for simplicity. Up to 500 markers is possible with the Luminex FlexMap 3D data acquisition instrument.
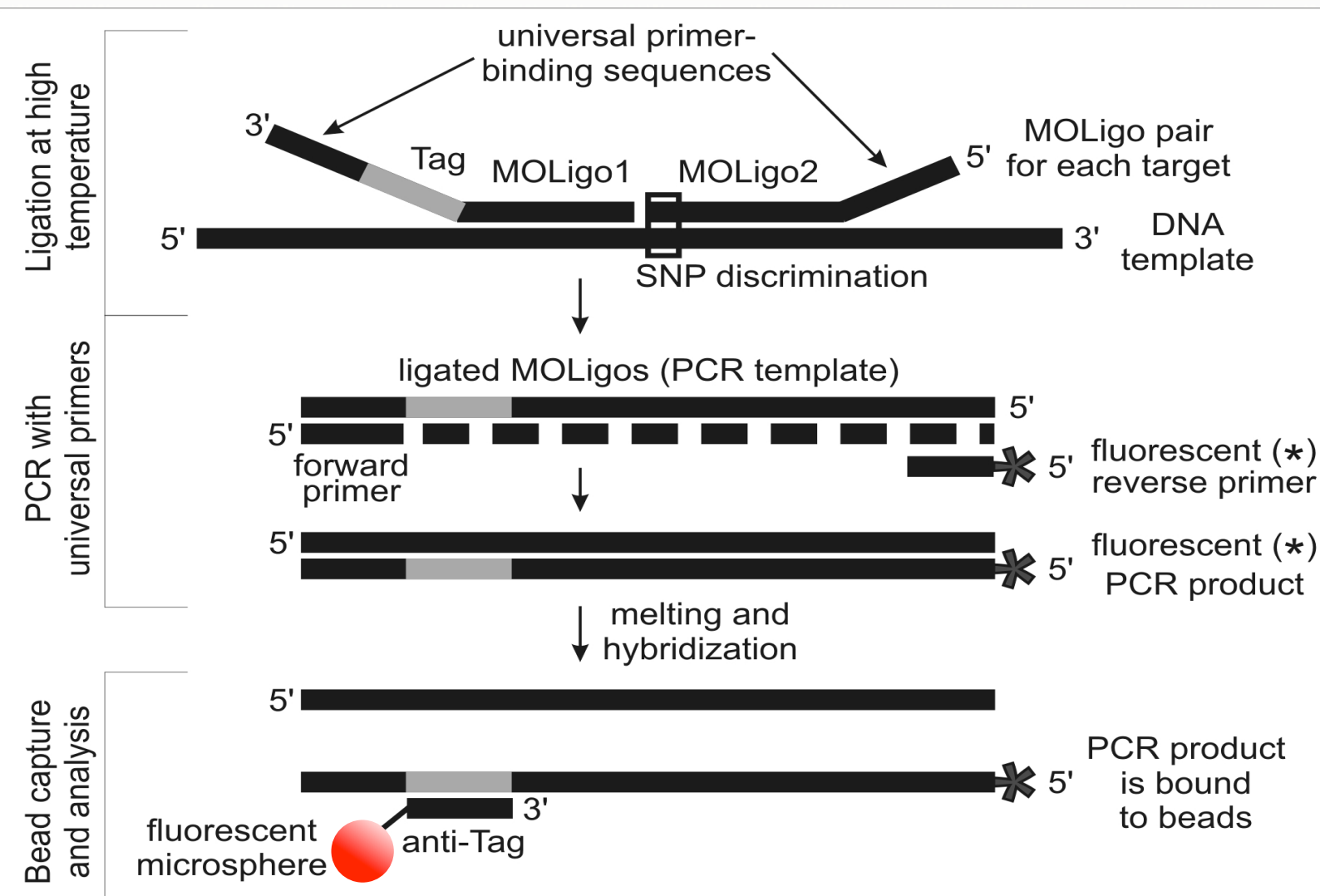


\section{Multiplexing reduces cost per data point (marker)}

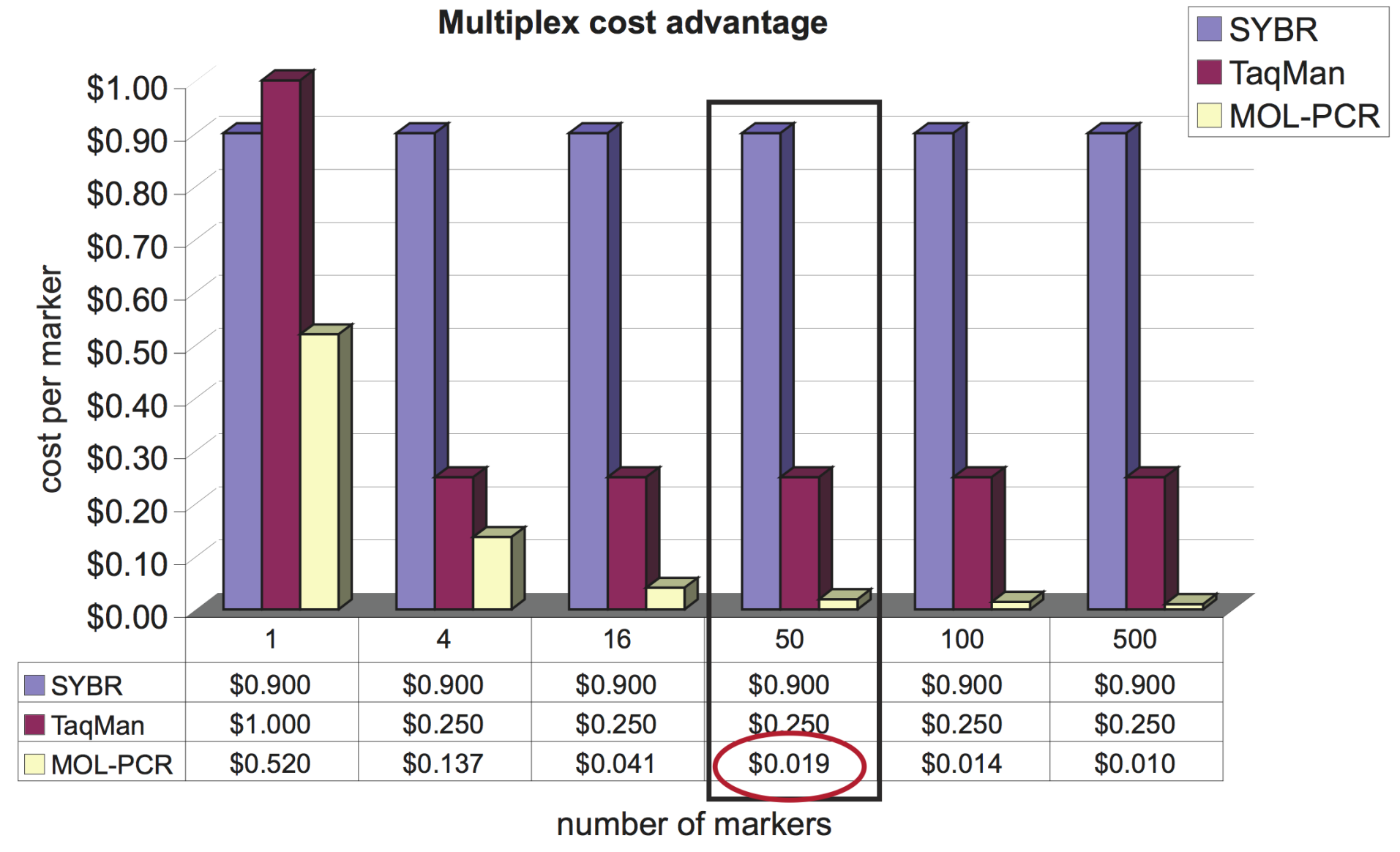




\section{Multiplexing reduces cost of ownership}
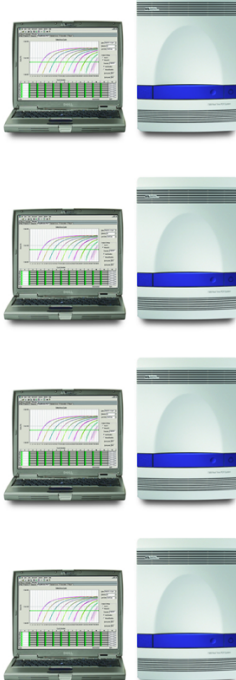

$$
\text { 4-plex Taqman }
$$
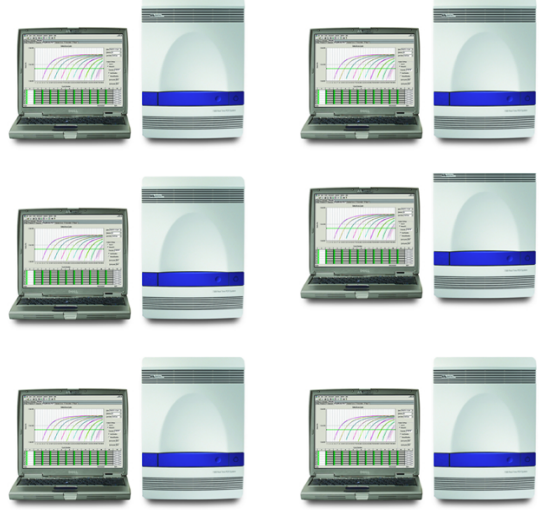

\section{Taqman (ABI 7500 throughput)}

1 plate

4 markers/well

1 plate/ 2 hrs

Operates $\sim 8 \mathrm{hrs}$

Operates 5 days/week

Capital Investment

Capital Investment for 76,800 markers/week $\$ 450 \mathrm{~K}$

Total Reagent Cost $=\$ 19,200 /$ week

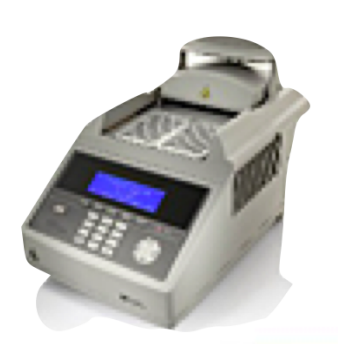

100-plex MOL-PCR

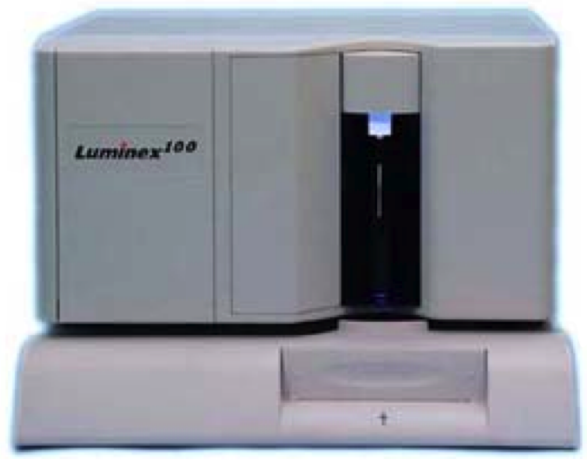

\section{MOL-PCR (2 PCR machines, 1 Luminex 100)}

4 plates

100 markers/well

Process 4 plates $/ 4 \mathrm{hrs}$

Operates $\sim 8 \mathrm{hrs}$

Operates 5 days/week

Capital Investment

\$75K total

Total Reagent Cost $=\$ 1,344 /$ week 


\section{Platform and assay comparison}

\begin{tabular}{|l|l|l|l|l|l|l|}
\hline Assay/platform & Specificity & Sensitivity & Instrument Cost & Operational cost & Multiplex & Throughput \\
\hline Taqman PCR & High & High & Moderate to High* & Moderate & Limited to 4 & Moderate \\
\hline qPCR (RT-PCR) & High & High & Moderate to High* & Moderate* & No & Moderate \\
\hline ELISA & Low to Medium & Low to Medium & Low & Low & Single to 2-plex & Moderate \\
\hline Sequencing & High & Low to Medium & Extreme & Extreme & $\begin{array}{l}\text { Possible with } \\
\text { some platforms }\end{array}$ & Extremely Low \\
\hline MOL-PCR & High $^{* * *}$ & Medium to High & Moderate & Low to Moderate & 500+ possible & Med to High \\
\hline
\end{tabular}

*Depends on required "bandwidth". Costs increase linearly with additional markers/samples.

**Large amounts of enriched or purified DNA are generally required, but whole genome amplification (WGA) is sometimes used to increase sensitivity. ***Includes SNP discrimination for higher resolution among pathovars, where needed.

\section{Cost of ownership, 4 week exercise (\$K) 400,000 samples/wk}

For MOL-PCR, cost per sample $\sim 2.50$ exclusive of sample collection, shipping, DNA purification, pipets, plates

\section{- Los Alamos} NATIONAL LABORATORY EST.1943
Taqman (4plex) 80

Taqman (4plex) 50

MOL-PCR 80plex

MOL-PCR 50plex

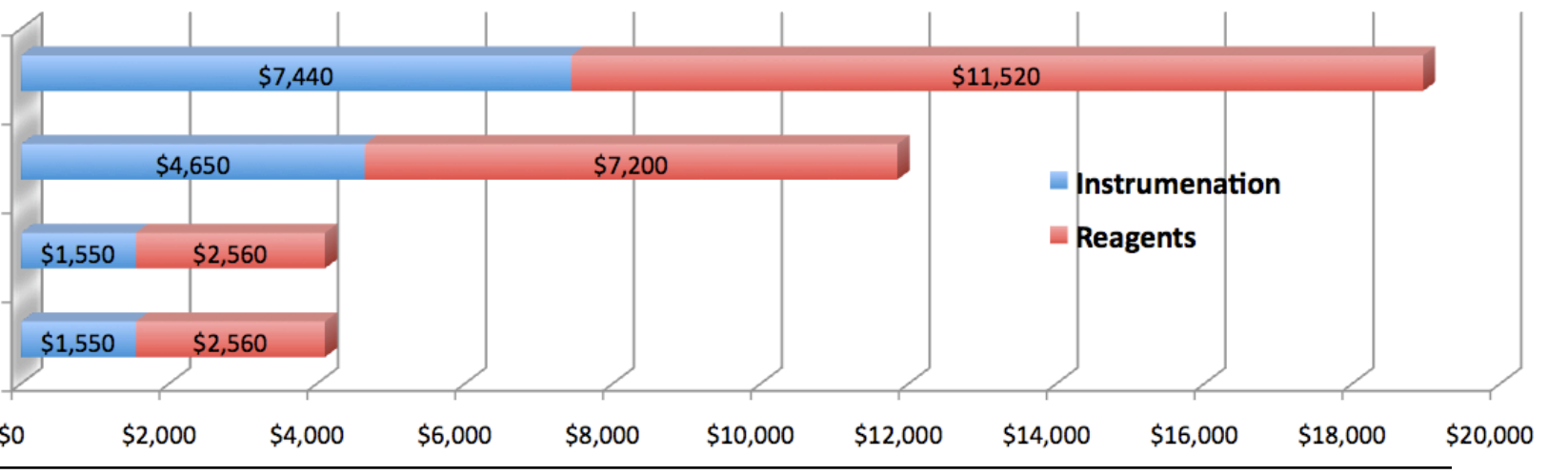

Operated by Los Alamos National Security, LLC for the U.S. Department of Energy's NNSA 


\section{Trade Space: Sample Throughput vs. Data}

Throughput vs. information content

Single marker sample analysis

High cost per marker

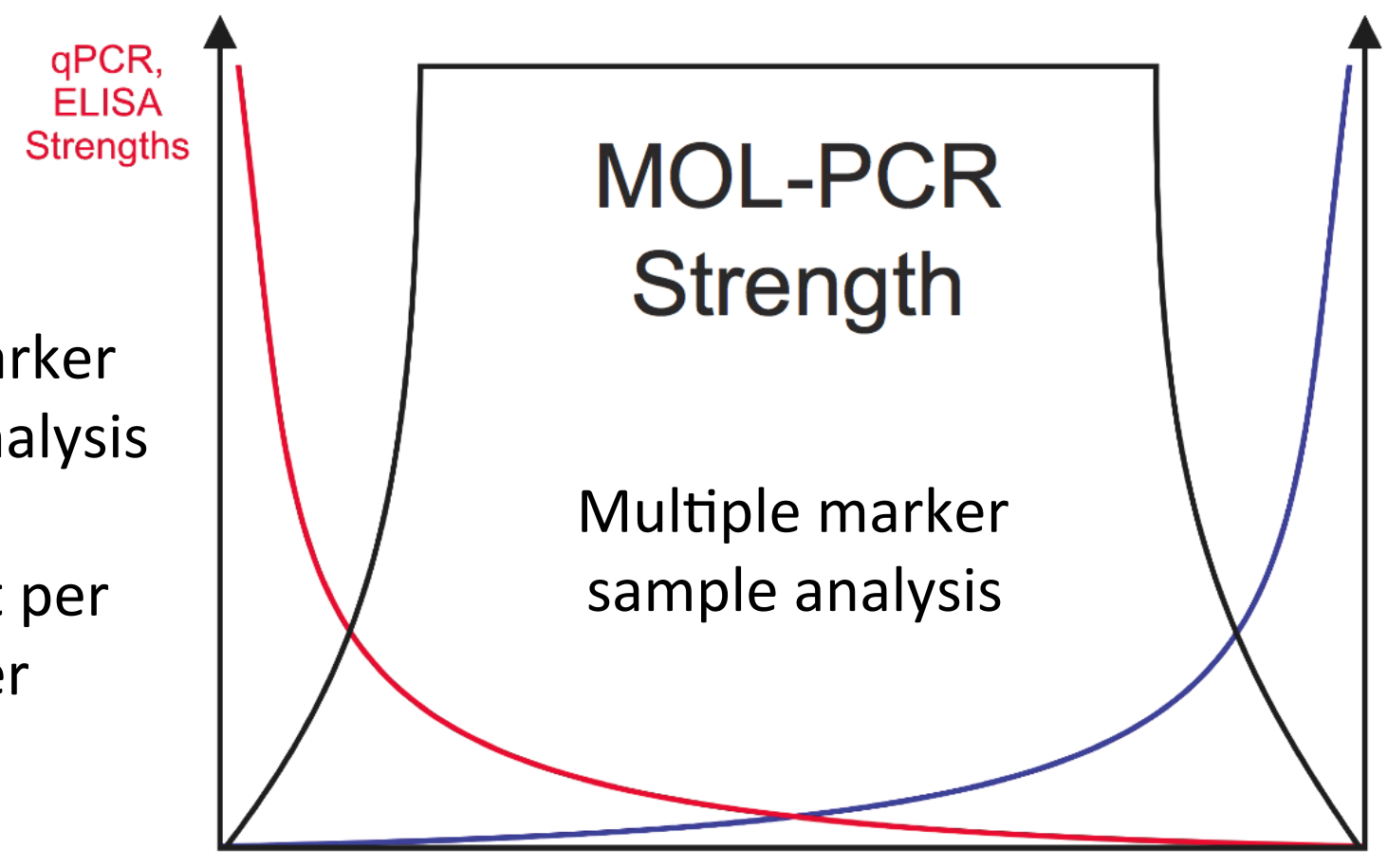

Throughput
Microarray

Strengths

Biomarker

Discovery

High cost per sample 


\section{Computational tools for assay design}

\section{MOLigoDesigner}

\section{A web-based tool for molecular signature design}

\section{MOLigo Design}

\begin{tabular}{|c|c|c|}
\hline Input & Tags & Generate \\
\hline
\end{tabular}

Input: the wild-type sequence, the SNP base and other mutations, or upload a file with this information Choose File no file selected

$>$ CLas gene 1 [INIT:1251]

TTCAAAAGATCCAGCAATTAGTGAAATTTACATTGTAGAGGGTGACTCTCCCGGTGGATCAGCAAAGCAA

GGGCGTCATCGTCACTTCCAAGCGATTTTACCACTGAAAGGTAAAATTATTAACGTTGAAAAGGCAAGAT

TAGATAAAATCTTATCTAACGATCAAGTCCGTACAATTATTACTCCAATTGGTACCAACATTGGCG

SNP1 C1330G [C1335A]

Click [HERE] to see an example input.

\section{Ligation conditions}

Oligo concentration

Monovalent salt concentration

Divalent salt concentration

Nucleotide triphosphates (dNTPs)

Specific region $\mathrm{T}_{\mathrm{m}(95 \%)}$

\section{MOLigo parameters}

Max specific region length

Min specific region length

Secondary structure boundary $T_{m}$

\begin{tabular}{l|ll} 
Range of $\mathrm{T}_{\mathrm{m}}(+/)$ & $1.4 \quad{ }^{\circ} \mathrm{C}$
\end{tabular}

Delta $T_{m}$ of specific regions

\section{no file selected}




\section{Example search result for one target SNP}

\section{MOLigoDesigner}

A web-based tool for molecular signature design

\begin{tabular}{|c|c|c|c|c|c|c|c|c|}
\hline MOLigo Results & \multicolumn{2}{|c|}{ Conditions } & Template & \multicolumn{2}{|c|}{\begin{tabular}{l|l} 
Summary & Download
\end{tabular}} & & & \\
\hline \multicolumn{2}{|c|}{ Oligo concentrations } & \multicolumn{2}{|c|}{$5 e-9 \mathrm{M}$} & \multicolumn{2}{|c|}{ Max specific primer length } & $36 \mathrm{bp}$ & Maximum trim 5' & bp \\
\hline \multicolumn{2}{|c|}{ Monovalent salt concentrations } & \multicolumn{2}{|c|}{$0.06 \mathrm{M}$} & \multicolumn{2}{|c|}{ Min specific primer length } & $12 \mathrm{bp}$ & Maximum trim $3^{\prime}$ & bp \\
\hline \multicolumn{2}{|c|}{ Divalent salt concentrations } & \multicolumn{2}{|c|}{$0.002 \mathrm{M}$} & \multicolumn{2}{|c|}{ Secondary structure boundary $\mathrm{Tm}$} & $45^{\circ} \mathrm{C}$ & Minimal trim length & bp \\
\hline \multicolumn{2}{|c|}{ Nucleotide triphosphates (dNTPs) } & \multicolumn{2}{|c|}{$0.0002 \mathrm{M}$} & \multicolumn{2}{|c|}{ Range of $\operatorname{Tm}(+l-)$} & $1.4^{\circ} \mathrm{C}$ & Optimal trim length & $\mathrm{bp}$ \\
\hline \multicolumn{2}{|c|}{ Ligation Tm } & \multicolumn{2}{|l|}{$55^{\circ} \mathrm{C}$} & \multicolumn{2}{|c|}{ Delta Tm of specific regions } & $5^{\circ} \mathrm{C}$ & Maximum LNA bases & bp \\
\hline
\end{tabular}

$\begin{array}{llllllllll}1260 & 1270 & 1280 & 1290 & 1300 & 1310 & 1320 & 1330 & 1340 & 1350\end{array}$

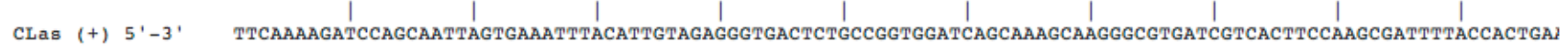

SNP1

G A

$\operatorname{SNP1(+)}$

CGTTTCGTTCCCGCACTACCAgTtAaggTTCGCTAAAATgG

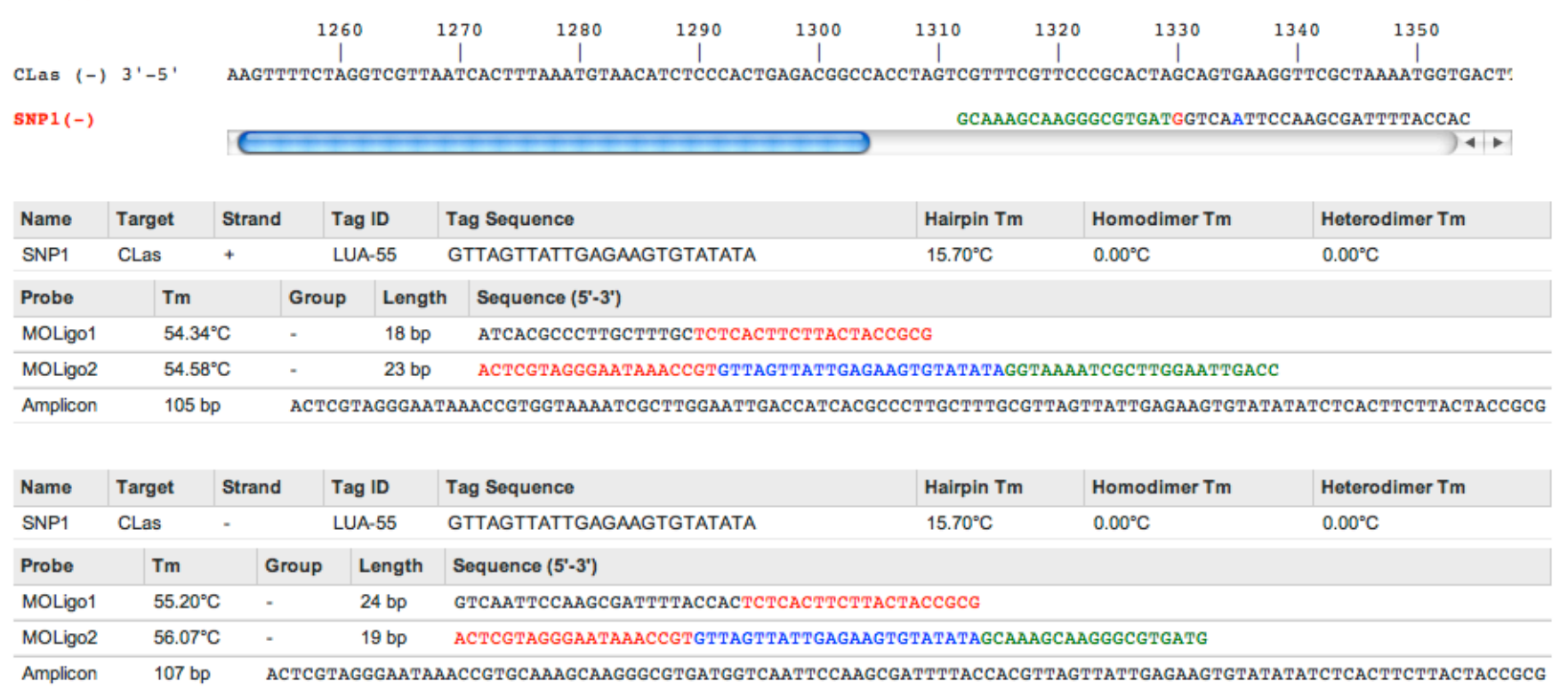




\section{Detection and characterization assay}

\section{Summary:}

-All pathogens detected

-Discrimination among most major clades of Liberibacter

-Inference of other Liberibacter clades possible

-Discrimination among major CTV clades

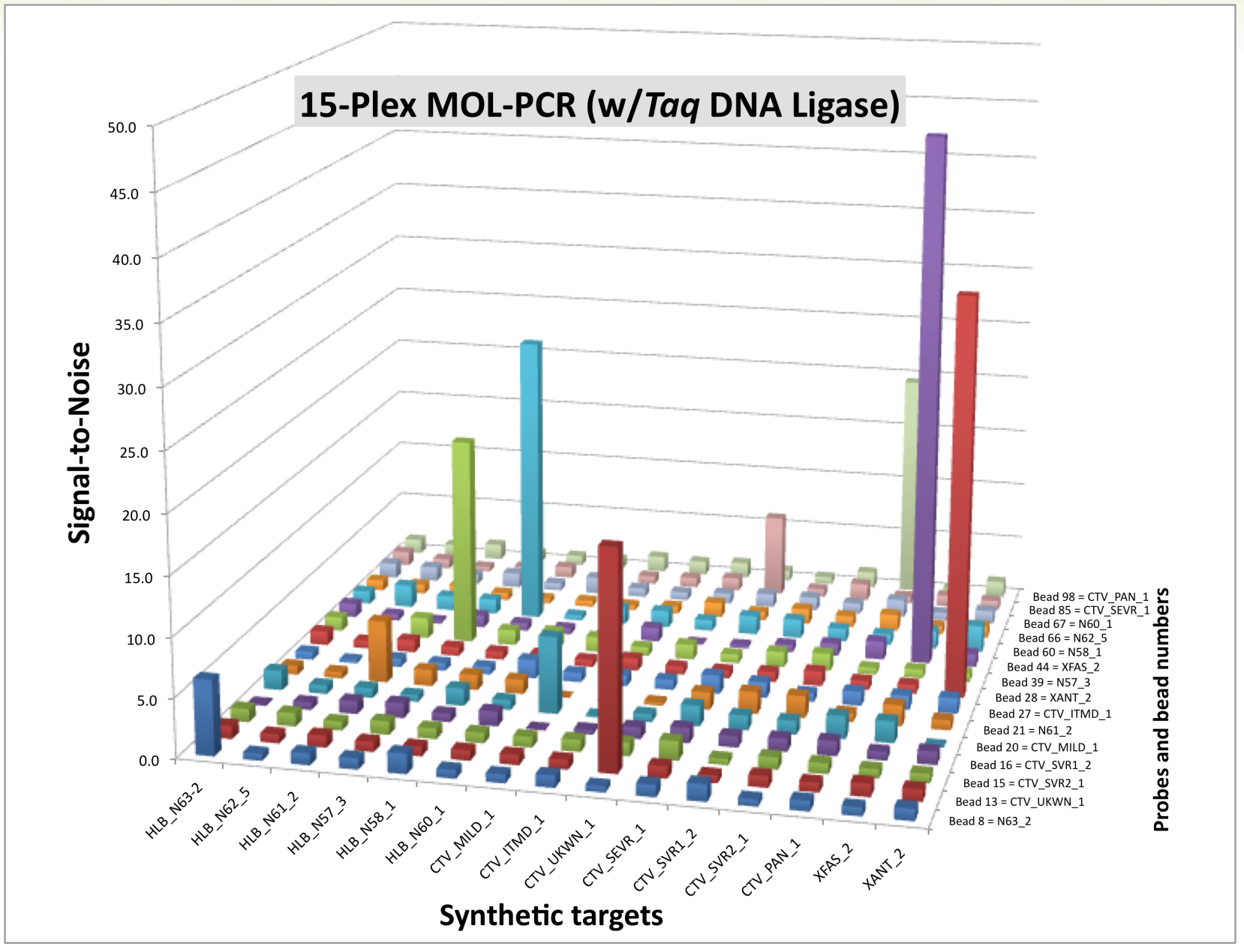




\section{Future needs in plant disease surveillance}

- Autonomous detection for pathogens and/or vectors

- Predictive tools for risk assessment and prioritization of resources

- Cooperative threat reduction partnerships for agricultural surveillance and security

- Worldwide sampling of crops, alternate hosts (backgrounds) to understand microbial/vector diversity and emerging pathogens

- Rapid, inexpensive, broad spectrum screening tools

- More sequence data

- Multidisciplinary solutions 


\section{LANL Science of Signatures}

Comprehensive measurement, analysis, and decision support capability through science of signatures.

\section{Overarching science goals}

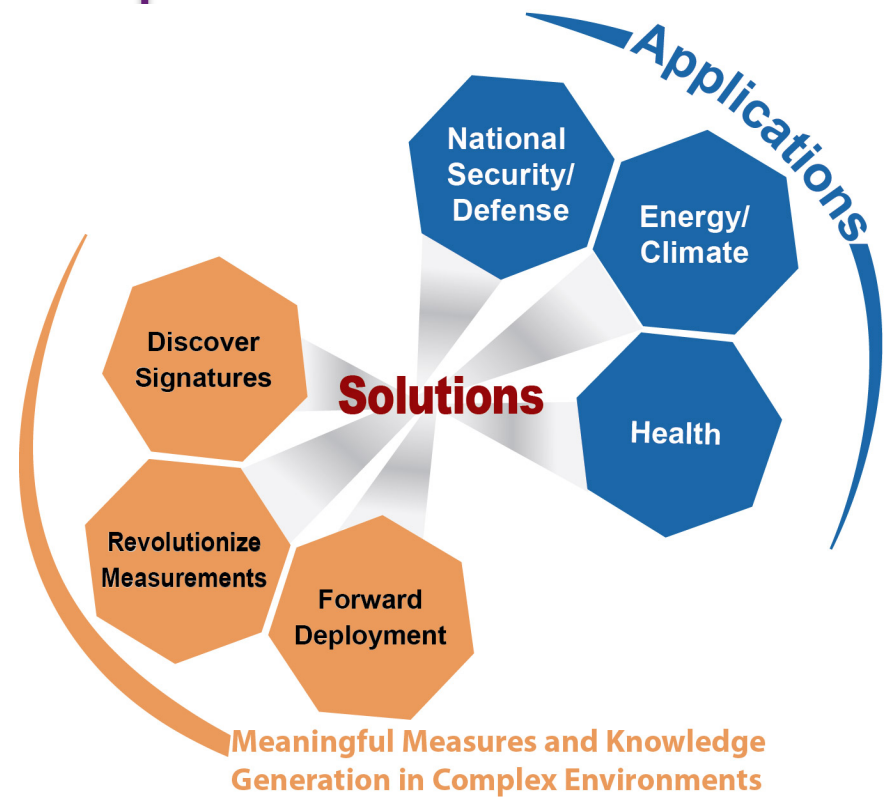

* Discover signatures

Identify signatures of CBRNE (chemical, biological, radiological, nuclear, and explosives) threats and of climate, energy and health security impacts. In a nutshell, signature discovery is determining those measurable phenomena that uniquely identify and characterize properties of complex environments.

\section{* Revolutionize measurements}

For threat-specific signatures, develop entirely new measurement technologies, methodologies, or strategies or develop transformational advances in the current state-of-the-art. In a nutshell, how can sensitive and specific measurements be made in entirely new ways and/or how can new phenomena (signatures) be measured?

\section{* Forward Deployment}

Make measurement technologies and methodologies practical through engineering. This includes prototyping of sensors and instruments for field deployment and systems integration of sensor networks. In a nutshell, how do we bring science advances to the real world in a way that provides feedback into signature discovery and/or revolutionary measurement technologies? 


\section{Forward Deployment: Agriculture}

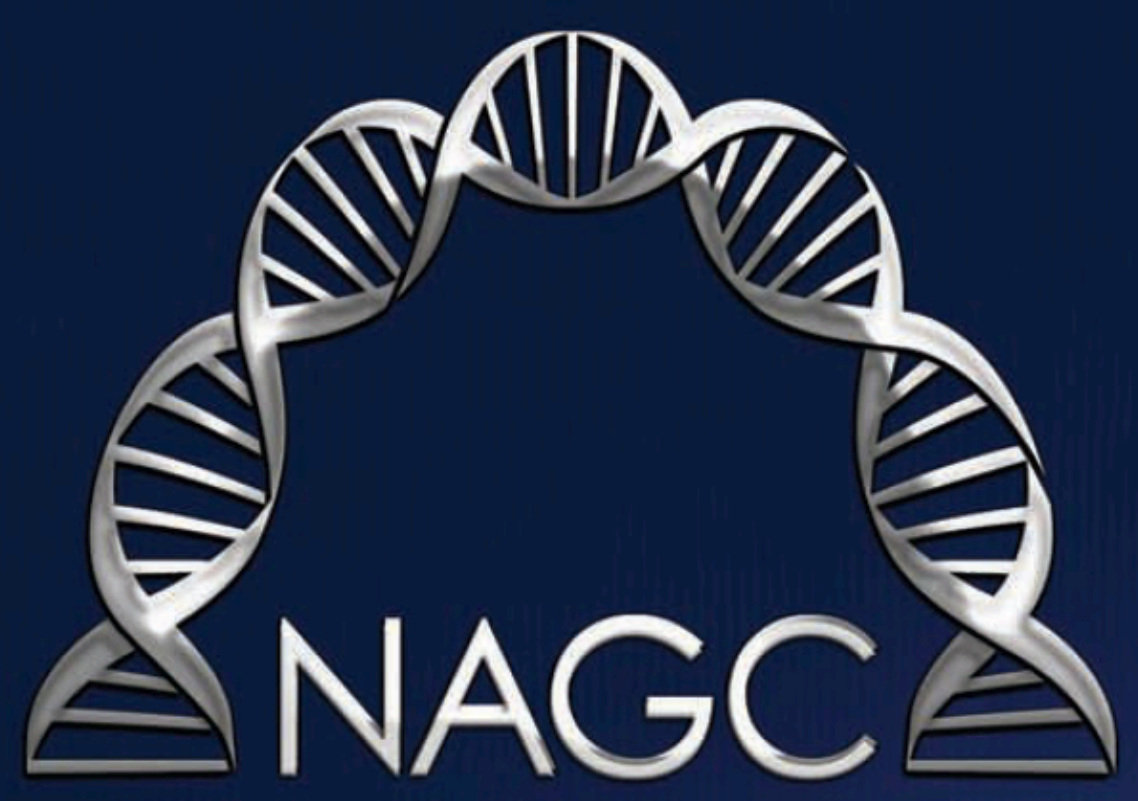

NATIONAL AGRICULTURAL

GENOTYPING CENTER 


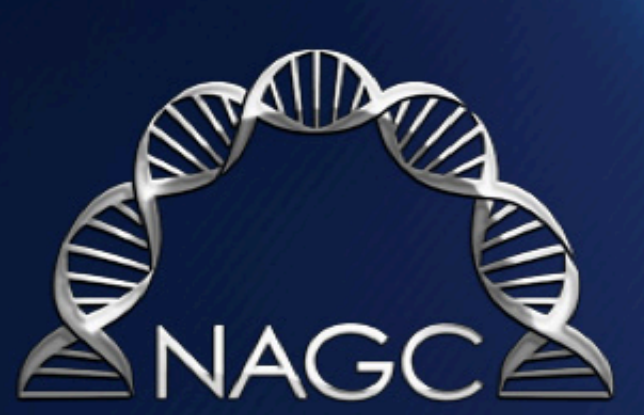

\section{NATIONAL AGRICULTURAL} GENOTYPING CENTER

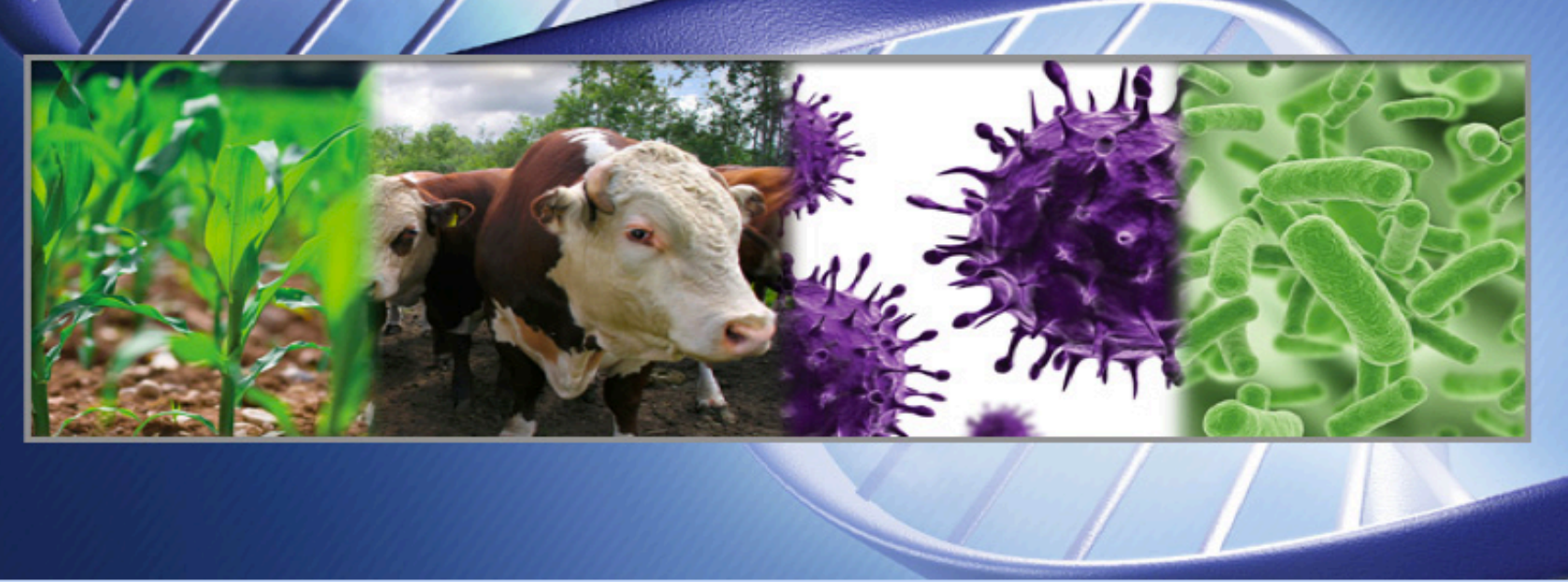

\section{| Home I Partners | Publications | Contact Us |}

\section{Los Alamos National Laboratory (LANL)}

The NAGC is partnered with Los Alamos National Laboratory (LANL), the premier research institution in the world with a proven track record in developing highthroughput genotyping technology. LANL has considerable experience in the design and testing of nucleic acid assays for the detection of human, animal and plant pathogens. The main funding for this work has come from the Department of Homeland Security (DHS), and a number of LANL assay designs have been transitioned by the DHS for use at the Centers for Disease Control and Prevention (CDC). Other support has come from the Citrus Research Board and from private industry. Over the past 10 years, LANL has designed assays for all of the key biothreat and public defense viral and bacterial pathogens.

The design methods employed at LANL rely extensively on computational techniques for genome comparison that were developed at LANL for the DHS and that are implemented on a large dedicated cluster of high performance computers. These methods are ahead of the current state of the art and allow LANL to identify assay designs that cannot be achieved elsewhere. The computational methods developed at LANL are applicable to any of the existing hybridization-based nucleic-acid assay methods (PCR, TaqMan, microarrays, NASBA, etc). However, in addition, LANL has considerable unique expertise with the MOL-PCR platform that will be deployed by this initiative. Tools have been developed and continue to be improved that are specific for MOL-PCR assay designs.

LANL will be responsible for the bioinformatics component of this initiative. Their work will be primarily focused on the design of nucleic acid assays. Additional tasks may involve sequence analysis for improved understanding of assay performance, database support, and support for development of counter-measures. Research needed to maintain state of the art capabilities may also be necessary.

\section{National Corn Growers Association (NCGA).}

The NAGC will benefit from this partnership by maintaining a direct link with the agricultural producers. NCGA represents 35,000 dues-paying corn farmers nationwide and the interests of more than 300,000 growers who contribute through corn checkoff programs. A partnership with the NCGA will facilitate access to farmers in 48 states. The Mission of the National Corn Growers Association is to create and increase opportunities for corn growers. The Vision of the National Corn Growers Association is that it will continue to be the recognized leader working in cooperation with its suppliers and customers to maintain sustainability and to achieve new business and profit opportunities for those it represents.

\section{Donald Danforth Plant Science Center (DDPSC)}

The Donald Danforth Plant Science Center in St. Louis, Missouri is a not-for-profit research institute. Scientists at the Center are engaged in research that strives to enhance the nutritional content of plants, increase agricultural production and to create a sustainable food supply. DDPSC will provide research expertise, administrative and operation support, and advising oversight. A partnership with the DDPSC will provide a rich, collaborative research environment and access to over 170 leading scientists. 


\section{Capabilities for agricultural surveillance reside across LANL}

- B-6 Genome Center

- B-7 Biosecurity and Public Health

- B-8 Environmental Science

- B-9 Advanced Measurement Science

- C Div instrumentation and analysis

- D-3 R\&D, testing, modeling

- D-6 risk modeling, knowledge integration

- EES modeling, plant stress and environmental research

- IAT-1 FIE; threat assessment, global awareness

- MPA-CINT materials and detection technologies

- P-21 aerosol science, microfabrication, field-based instrument development

- T-6 research and modeling

- Tech Transfer Program Office 


\section{Outline}

- Scope of the problem

- Need for technical solutions

- LANL technology solutions 


\section{Greening and Canker in Florida}

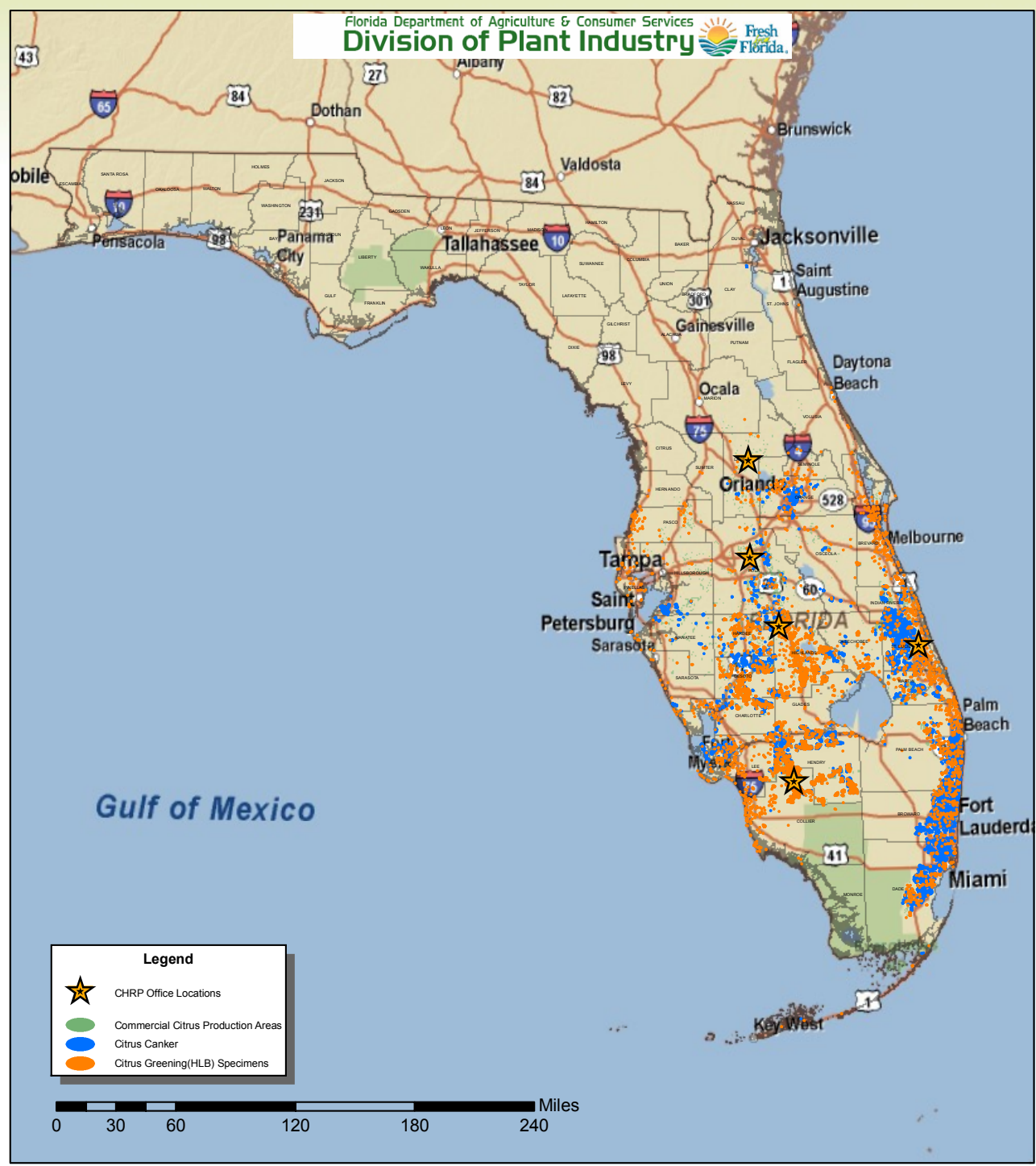

